\title{
Evaluation of propofol, ketamine hydrochloride and propofol, midazolam combinations for clinical anesthesia in dogs
}

\begin{abstract}
The present study was conducted to compare the anesthetic efficacy of propofol with ketamine hydrochloride and propofol with midazolam combinations for clinical anesthesia in dogs. During 2014, a total of 30 adult, apparently healthy stray dogs of either sex were selected. These animals were randomly divided into two groups (A and B), having fifteen animals in each group. The dogs of groups A were treated with propofol@4 mg/kg BW IV in combination with ketamine hydrochloride @ 4mg/ $\mathrm{kg}$ BW. Animals of group B were given intravenous injection of propofol @ $4 \mathrm{mg} / \mathrm{kg}$ BW IV in combination with mizadolam @ $0.2 \mathrm{mg} / \mathrm{kg} \mathrm{BW}$. As the dogs were injected intravenous, the time was noted, and used as reference to describe the changes in various reflexes. During whole of the experiment, the animals were closely monitored. The effects of anaesthetic agents on various body reflexes like corneal reflex, pupil reflex, pharyngeal reflex, mandibular tone reflex, tongue pinch reflex, anal pinch reflex and tail flaccidity were recorded. In addition to these, following other parameters studied were 1) Time taken for the induction of surgical stage of anaesthesia 2) Duration of surgical stage of anaesthesia 3) Recovery from anaesthetic condition to normal reflexes 4) State of respiration, temperature and pulse rate before, during and after induction of anaesthesia. Groups A showed rapid inductions, prolonged surgical stages and late recovery in most of the reflexes and group B showed smooth recovery than A. Group B showed smooth induction, short surgical stages and rapid recovery. Group B also showed some disturbances in respiratory and cardiac activity of the animals. It was concluded that propofol in combination with ketamine hydrochloride is a safe anaesthetic agent as compared to propofol with midazolam for canines for prolonged surgical procedures.
\end{abstract}

Keywords: dog, anesthesia, propofol, ketamine hydrochloride, midazolam
Volume 4 Issue I - 2019

\author{
Abdul Asim Farooq,' Tanveer Ahmad,' \\ Muhammad Saleem Akhtar,' Ejaz Ahmad, \\ Saima Inayat, ${ }^{2}$ Sayyed Aun Muhammad, ${ }^{3}$ \\ Muhammad Mazhar Ayaz, ${ }^{3}$ Mushtaq Hussain \\ Lashari, ${ }^{4}$ Masood Akhtar ${ }^{4}$ \\ 'Faculty of Veterinary Sciences, Bahauddin Zakariya University, \\ Multan, Pakistan \\ ${ }^{2}$ Department of Dairy Technology, University of Veterinary and \\ Animal Sciences, Lahore, Pakistan \\ ${ }^{3}$ College of Veterinary and Animal Sciences, Jhang, Pakistan \\ ${ }^{4}$ Department of Life Sciences, The Islamia University of \\ Bahawalpur, Pakistan
}

Correspondence: Muhammad Saleem Akhtar, Faculty of Veterinary Sciences, Bahauddin Zakariya University, Pakistan, Emaildrsaleemakhtar@bzu.edu.pk

Received: November 21, 2017 | Published: February 28, 2019

\section{Introduction}

Anaesthesia is an indispensable pre-requisite to most of the surgical interventions, both in humans and animals, so that the surgeon can perform surgical intervention with maximum precision and sagacity. Anaesthetics are available for both parenteral as well as inhalation routes in canine surgery. Due to meager facilities available for field veterinarians in Pakistan, intravenous anaesthetics are preferred because of their early and safe induction. Ketamine hydrochloride has been the sole anaesthetic agent so far relied upon by the veterinarians for most of surgical interventions. Its unavailability or irregular availability in local market renders the veterinary surgeons incapable of performing any intervention on canine surgical patients. This situation compels the veterinary surgeons/ practitioners to look for some other suitable and safe alternative readily procurable from the market having better or an equivalent spectrum of anaesthesia. Propofol is a unique non-barbiturate, non-steroid, short-acting general intravenous anaesthetic agent. ${ }^{1}$ It is associated with a rapid smooth induction and a rapid recovery. ${ }^{2}$ More advantageously, it is readily available in the market. Anaesthetic stage duration of propofoland midazolam could be enhanced if used in combination with ketamine hydrochloride. This hypothesis lead us to study the anaesthetic efficacy of propofol in combination with ketamine hydrochloride and to compare it with combination of propofol mizadolam in dogs.

\section{Materials and methods}

\section{Experimental animals}

A total of 30 adult, apparently healthy stray dogs of either sex were selected. These animals were randomly divided into two groups (A and B), having fifteen animals in each group. The experimental animals were kept under the same managemental and nutritional regimens during the trials. Food and water were withheld for 24 and 12 hours, respectively prior to the induction of anaesthesia to avoid regurgitation and respiratory embarrassment. These dogs were casted on lateral recumbency, with head slightly lower than the hind quarters. They were allowed to relax for some time to overcome excitement. The normal respiration rate, pulse rate and temperature of each dog were recorded.

\section{Administration of anaesthesia}

The dogs of groups A were treated with propofol @ $4 \mathrm{mg} / \mathrm{kg}$ BW IV in combination with ketamine hydrochloride @ $4 \mathrm{mg} / \mathrm{kg} \mathrm{BW}$. Animals of group B were given intravenous injection of propofol @ $4 \mathrm{mg} / \mathrm{kg}$ BW IV in combination with mizadolam @ $0.2 \mathrm{mg} / \mathrm{kg} \mathrm{BW}$. As the intravenous injection was made, the time was noted, and was used as reference to describe the changes in various reflexes. A team of trained personnel were deputed to record observations for various clinical parameters at 5 minutes interval till the complete normalization of the reflexes.

\section{Post treatment monitoring}

During whole of the experiment, the animals were closely monitored. The effects of anaesthetic agents on various body reflexes like corneal reflex, pupil reflex, pharyngeal reflex, mandibular tone reflex, tongue pinch reflex, anal pinch reflex and tail flaccidity were recorded. In addition to these, following other parameters were also be studied 
I. Time taken for the induction of surgical stage of anaesthesia

II. Duration of surgical stage of anaesthesia

III. Recovery from anaesthetic condition to normal reflexes

IV. State of respiration, temperature and pulse rate before, during and after induction of anaesthesia.

The data thus collected was analysed statistically.

\section{Results}

\section{Ocular reflexes}

\section{Corneal reflex}

The corneal reflex was absent within two minutes in dogs of group A post medication and remained absent for almost the same time duration in group A as compared to group B in which it remained absent for a significantly longer time $(p<0.05)$. Then this reflex recovered in a short time in group A but group B showed late recovery.

\section{Pupil reflex}

Pupil dilated in a significantly shorter time in dogs of group A and $\mathrm{B}$ after administering respective anaesthetic agents. It remained dilated for longer duration in both groups. Then it started to constrict and became normal rapidly in groups $\mathrm{B}$, while group $\mathrm{A}$ showed late recovery $(\mathrm{p}<0.05)$.

\section{Reflexes of head region \\ Pharyngeal reflex}

For surgical stage, group A and B showed longer duration but recovery was rapid group $\mathrm{B}$, as compared to group $\mathrm{A}$ which recovered later $(\mathrm{p}<0.05)$.

\section{Mandibular tone reflex}

Induction of anaesthetic condition in terms of mandibular tone reflex was rapid in both group and this reflex remained absent for longer time in both groups $(\mathrm{p}<0.05)$. The differences between both groups were non-significant. Then recovery of the mandibular tone reflex occurred at the same intervals in both the groups and there was no difference between them.

\section{Tongue pinch reflex}

After administration of respective anaesthetic agents, this reflex became absent at the same time in both the groups and remained absent for prolonged duration in animals of both groups.

\section{Hind quarter reflexes}

\section{Anal sphincter reflex}

In terms of anal sphincter reflex, both the groups took almost the same time for induction of anaesthetic stage after anaesthetic administration. Then it remained absent for prolonged period and recovery was delayed in both groups $(\mathrm{p}<0.05)$.

\section{Tail flaccidity}

In groups $\mathrm{A}$ and $\mathrm{B}$, post medication the flaccidity of tail was achieved earlier. But recovery was delayed in both groups $(\mathrm{p}<0.05)$.

\section{Pulse rate}

There was an increase in pulse rate in both groups after administration of respective anaesthetic agents. A sharp increase in pulse rate was noted within 5 minutes in group B, and this trend was observed for 15 minutes. Groups A did not show any observable difference in pulse rate up to 40 minutes post medication.

\section{Respiration rate}

A fall in respiration rate was observed in dogs of both the groups after administration of respective anaesthesia. Group A showed decreasing trend up to 15 minutes and then it started increasing and became normal after 30 minutes. Respiration rate decreased up to 15 minutes in group B and then increased but remained lower than the baseline up to 40 minutes.

\section{Body temperature}

Body temperature decreased in dogs of both groups within 5 minutes of administration of anaesthetic agents. But this decrease was marked in group A, whereas group B showed continuous decrease in body temperature up to 20 minutes. Groups B showed increasing trend and body temperature became normal within 40 minutes.

\section{Discussion}

Selection of anaesthetic agents depends upon species or breed of the animal, nature of surgical operation, susceptibility of the patient to the action of anaesthetic drug and health status of the animal to be anaesthetized. ${ }^{1,2}$ In our study, animals of groups A and B given propofol alone at the dose rate of 6 and $10 \mathrm{mg} / \mathrm{kg} \mathrm{BW}$, respectively, showed rapid and smooth induction. All body reflexes disappeared and animals were in perfect surgical stage for a short duration. One of the disadvantages of propofol is that it may cause apnoea, ${ }^{3}$ which was also observed in our study in two animals of group B. These animals showed apnoea of 50-120 seconds. The difference in our observation from previous studies was that apnoea occurred only in animals which were administered with a higher dose of propofol. Incidence and apnoea was not observed in groups A and C. These results showed that administration of ketamine with propofol avoids respiratory depression, which was seen when propofol was used alone. ${ }^{4}$ Recovery was smooth and rapid in propofol administered animals, ${ }^{1,2}$ and it was also observed in our study. These results showed that in canine surgery propofol can be safely used for smooth induction of anaesthesia and significantly quicker recovery and earlier return of psychomotor function compared with thiopental but for shorter duration. No nausea and vomiting were seen during propofol anaesthesia, which is similar to the findings of. ${ }^{5-11}$

The findings of present study clearly demonstrated that propofol in combination with ketamine hydrochloride is a safe anaesthetic agent as compared to propofol with midazolam for canines for prolonged surgical procedures.

\section{Acknowledgments}

The authors wish to acknowledge Research Fund of Bahauddin Zakariya University, Multan, Pakistan for supporting this research.

\section{Conflicts of interest}

There is no conflict of interest for this manuscript.

\section{References}

1. Hofmeister EH, Williams CO, Braun C, et al. Propofol versus thiopental: effects on peri-induction intraocular pressures in normal dogs. Veterinary Anaesthesia Analgesia. 2008;35:275-281.

2. Van Natta ME, Rex DK. Propofol alone titrated to deep sedation versus propofol in combination with opioids and/or benzodiazepines 
and titrated to moderate sedation for colonoscopy. American Journal Gastroenterology. 2006;101:2209-2217.

3. Sams L, Braun C, Allman D, et al. A comparison of the effects of propofol and etomidate on the induction of anesthesia and on cardiopulmonary parameters in dogs. Veterinary Anesthesia Analgesia. 2008;35(6):488-494

4. KazutoY, Mayumi N, Hiroko T, et al. Medetomidine with thiopental, ketamine, or propofol as premedication and induction for inhalation anesthesia in dogs. $J$ Japan Veterinary Medical Association 2001;54:282-287.

5. Ronald D, Miller MD. Anaesthesia. $5^{\text {th }}$ edn. Churchill Livingstone. 1981:690-693.

6. Ghaffari MS, MA Rezaei, AH Mirani, et al. The effects of ketaminemidazolam anesthesia on intraocular pressure in clinically normal dogs. Veterinary Opthalmology. 2010;13(2):91-93.
7. Gunderson EG, Lukasik VM, Ashton MM, et al. Effects of anesthetic induction with midazolam-propofol and midazolam-etomidate on selected ocular and cardiorespiratory variables in clinically normal dogs. American Journal Veterinary Research. 2013;74(4):629-635.

8. Hofmeister EH, Weinstein WL, Burger D, et al. Effects of graded doses of propofol for anesthesia induction on cardiovascular parameters and intraocular pressures in normal dogs. Veterinary Clinical Analog. 2009;36(5):442-448.

9. Kushwaha JP, Malik V, Singh B. Evaluation of midazolam and propofol in different combinations for clinical anaesthesia in dogs. Indian Journal of Veterinary Surgery. 2012;33(2):77-81.

10. Peter WH, Lisa CF, John AEH. Induction of anesthesia with diazepam ketamine and midazolam ketamine in grey hounds. Veterinary Surgery. 1991;20(2):143-147.

11. Short CE, Bufalari A. Propofol anesthesia. Veterinary clinic North American Small Animal Practice. 1999;29(3):747-778. 